are of relatively considerable antiquity, and represent the results of geological activity, including an epoch of low temperature, in eastern and southern England.

\section{Current Science}

Wrre the publication of its July issue, our Indian contemporary, Current Science, enters upon its fifth year. Founded to supply an obvious need in the scientific renaissance of India, Current Science is almost unique in that its editor is assisted by a board comprising the majority of the best-known Indian men of science. The July issue contains much of interest not only to India but also to the West. The leading article comments on the inauguration, by his Excellency the Viceroy, of a Nutrition Advisory Committee. The outstanding investigations of Sir Robert McCarrison in Coonoor have in recent years focused the attention of Indian public opinion upon the importance of adequate feeding for national efficiency. Inadequate nutrition, combined in many areas with endemic malaria, is known to be the cause of the poor physique of many classes. The Royal Society is now assisting in the investigation of the intricate problems of malaria control, and will doubtless co-operate with this new Advisory Committee. Another article in the July issue, of more than local interest, is the summary of a lecture given by Prof. Birbal Sahni on the Karewas of Kashmir, where the geology of the Karewas series in the Himalayas is discussed from the point of view of the botanist. We congratulate the editor of Current Science on the high standard of the journal, which, if maintained, ensures its continued success.

\section{Philosophy and Quantum Theory}

If philosophy is, as Descartes claimed, the 'universal science', it should be able to assimilate all new discoveries in the special sciences. There was not much difficulty in dealing with classical physics. When the theory of relativity was put forward, it was soon found that philosophical ideas could be rearranged to find it a place, and even a welcome, but what is to be the attitude to a theory which denies continuity and determinism ? An attempt, admittedly incomplete, to answer these questions has been made by R. Dugas ("La méthode dans la mecanique des quanta". Actualités scientifiques et industrielles, 283. Paris : Hermann et Cie., 1936). Following Meyerson, complete indeterminism is rejected, and replaced by aggregates ruled by laws of probability. If there is no law, there is no science. Other difficulties arise when we try to discover the basis of Schrodinger's equation. Are we to say that our equations know more than we do, and that, without understanding them, we can rely upon them to furnish the correct results? Are we to believe in panmathesis, and in a universe in which electrons and matter have no real existence, but are merely names for mathematical symbols ? The trouble with questions such as these is that all the available evidence appears to point to the conclusions that are repugnant to common sense.

\section{Photomicrographic Reproduction of Scientific Papers}

Following on the formation of the Documentation Division of Science Service, a programme of testing mechanical methods of applying photomicrographic duplication of scientific literature is being developed, including a camera for copying upon $35 \mathrm{~mm}$. film, supplementary apparatus such as a book holder for the camera, film container, etc., a reading machine, microfilm viewer, projection printer, and developing and processing apparatus for $35 \mathrm{~mm}$. microfilm and paper projection points. Procedure has already been developed for the publication of scientific material otherwise unable to receive publication in full. Editors of journals or institutions deposit typescripts of those papers or portions of papers which they are unable to publish promptly or completely. With an abstract or summary, they publish a statement that additional matter, illustrations, tables, etc., are available on request from Science Service if the document number is stated and the price remitted. The document is assigned a number by Science Service and on receipt it is photographed on $35 \mathrm{~mm}$. film master negative. The original document is then deposited elsewhere as a safeguard. The photomicrographic duplication is economical when up to twenty-five copies at a time are required and has the further advantage that the document is continuously in print as the negative can be used to supply a copy on demand at any time.

THE relation of microfilms or photo-copies prepared in this way to priority in scientific discoveries has been raised. Opinion is expressed in a note issued by Science Service that microfilm or photo-copy publication is a printed publication in the true sense, and that by considerably reducing the time between the submission of a paper to a journal and the date of publication of the discovery announced therein, this type of publication will be of great assistance in eliminating controversies such as have arisen in the past concerning individual claims for priority in making discoveries. If any doubt exists as to whether photomicrographic publication is a 'printed publication', it is urged that this doubt could be removed by scientific societies merely agreeing among them. selves that, in so far as priority in their fields is concerned, photomicrographic publication should be accorded the same weight and effect as publication in a printed journal.

\section{Wind Erosion in South Australia}

WIND erosion is becoming an increasing danger in the semi-arid regions which form the world's chief granaries. In North America, the Argentine and to a less extent in Russia, the fertile prairie soils are rapidly being swept away as the result of destroying the original grass cover. A similar fate is overtaking vast pastoral regions in South Australia, due to overstocking. The gravity of the situation is revealed in a note by F. N. Ratcliffe, received from the Commonwealth Council for Scientific and In. dustrial Research. The worst erosion has been in the 'bush' country, where twelve drought years have so 
lowered the stocking capacity that overstocking on established farms is now almost unavoidable. Rabbits have added to the evil, the vegetation cannot recover after grazing, and natural regeneration of both shrubs and grasses has virtually ceased. Large areas have become barren deserts, and no measures are available for their reclamation. The evil might be checked by adopting a lower stocking policy; but the only hope for the already denuded areas is to introduce perennial exotic plants capable of stabilizing the large sand drifts, and withstanding rabbits and a very low and uncertain rainfall. The chance of discovering such plants is remote, and even if discovered, "there would remain the problem of their dissemination through vast areas with no regular growing season and an unimproved capital value rarely exceeding 2s. per acre".

\section{Mining in Canada}

WE have received the Report of the Department of Mines of the Dominion of Canada for the fiscal year ended March 31, 1935, and taken as a whole it may be said to be thoroughly satisfactory. The Report shows that the rise in the price of gold has caused renewed activity in that industry and states that "Canada's gold industry is contributing to the prosperity, not only of the communities in which operations are centred, but to the industrial life of the nation as a whole". Canada apparently is also reopening some of the silver camps for which it was famous a few years ago, but the "Department's work in fuels and non-metallics is becoming of increasing economic importance", and there has been a relatively small number of ore treatment investigations in connexion with base metal ores. There are full reports of the various divisions of the Department of Mines, commencing with a Bureau of Economic Geology, the National Museum of Canada and Mines Branches proper, together with an Explosives Division, an Editorial Division and an Accounting Division, which latter shows that something like a million dollars was available for the expenditure of the Department of Mines, and that nearly all of it was utilized. It is interesting to note that the Fuels and Fuel Testing Division was busily engaged throughout the year in question.

\section{Cotton Research in India}

INDIA is the second largest cotton growing country in the world, and the importance of the industry led the Indian Cotton Committee to set up a Technological Laboratory at Matunga some ten years ago. Research work and tests of direct importance to the cotton breeder, merchant and mill owner have been carried out in collaboration with the provincial agricultural departments, and a brochure has just been published by the Committee giving a full account of the activities of the Laboratory since its inception (Bombay: Indian Central Cotton Committee. 2 rupees). The two main objects of the work are to undertake spinning tests on improved varieties of cotton, and to establish relationships between the measurable fibre characteristics and the spinning quality. This second object aims at dispensing with the necessity of making spinning tests on large numbers of new strains, as it is hoped to be able to assess the performance of the cotton from a know. ledge of its fibre properties. The development of the work may be judged from the fact that during 1933-34, 166 samples were tested in connexion with trade and technological problems, compared with only 28 in 1924-25, while as regards agricultural samples, 366 were tested in 1933-34, compared with 46 in the 1924-25 season. The problem of averting the possible danger of the introduction of the cotton bollweevil through imported American bales has been successfully attacked. A satisfactory method of fumigation has been developed, and legislation enacted to ensure that all cottons imported from America are so treated. The brochure concludes with a complete list of publications issued from the Laboratory since 1925.

\section{The Science Museum Library}

ON entering a library for the purpose of obtaining information on a given subject, the first things the visitor wishes to know are what books or pamphlets the library possesses relating to the subject, and how is he to obtain them. There are usually card indexes available, but even with these at his disposal the reader may well be at sea unless he possesses a key to the system on which they are arranged. The publication of a new edition of the "Classification for Works on Pure and Applied Science in the Science Museum Library" (London : H.M. Stationery Office. 5s. net.) provides such a key to the finest science library in Great Britain. It should be studied by every one who uses the Library. It contains an explanation of the Universal Decimal Classification of the International Institute of Documentation in use at the Library, a list of about six thousand classes into which knowledge is divided for the purpose of indexing, and a copious alphabetical index comprising some five thousand entries. In the preface to the "Classification", Dr. S. C. Bradford says : "The titles on the cards in the Subject Catalogue are numbered and arranged in accordance with the Universal Decimal Classification. Under each number the titles are in chronological order. To ascertain what books the Library possesses on a given subject, readers are recommended to look first in the index, and then refer to the classification, before consulting the cards." By following this advice, those not already familiar with the system used in the Science Museum Library will undoubtedly save themselves both time and labour. It may be added that, in the last Report on the Science Museum, it was stated that the Library now possesses 252,515 volumes, the total of periodicals currently received is 9,468 , while the Subject Matter Index contains 2,248,423 references.

\section{Progress in France of Electricity Supply}

Av account of electricity supply in France appears in World Power of July, as a translation of a paper in La Journée Industrielle. In 1923 the total installed capacity of electrical generating stations was $4 \frac{1}{2}$ million kilowatts. This increased to $10 \frac{1}{2}$ million in 1935. There are 15 thermal and 5 hydro-electric 